\title{
Pessoas com Deficiência Visual: barreiras para o lazer turístico
}

\author{
People with Visual Impairment: barriers to leisure tourism
}

Personas con Discapacidad Visual: barreras al turismo de ocio

\author{
Marina Dias de Faria ${ }^{1}$ \\ Paulo César Motta ${ }^{2}$
}

\begin{abstract}
Resumo
A presente pesquisa teve como objetivo identificar os fatores que mais restringem o consumo de serviços de lazer turístico por pessoas com deficiência visual. O turismo inclusivo caminha a passos lentos no Brasil, a despeito de 24 milhões de brasileiros serem pessoas com deficiências - das quais $48 \%$ apresentam deficiência visual, foco desse estudo. Na presente pesquisa foi elaborado um questionário com o auxílio da revisão de literatura e de entrevistas com oito informantes-chaves. Esse questionário continha 27 assertivas, cobrindo diversos aspectos de restrição ao turismo para pessoas com deficiência visual. O questionário foi enviado por email para pessoas com deficiência visual, obtendo-se 202 respostas válidas. Os resultados da presente pesquisa apontam sete fatores de restrição ao consumo de serviços de lazer turístico para pessoas com deficiência visual: Tempo, Recursos Financeiros, Questões Pessoais, Importância da Companhia, Barreiras Atitudinais, Barreiras Arquitetônicas e Atendimento. As maiores médias foram atribuídas aos fatores Atendimento e Importância da Companhia. Diante dos resultados, é possível sugerir que, no setor estudado, faltam investimentos em treinamento para que os funcionários de linha de frente estejam capacitados a atender os deficientes visuais de forma adequada. Ao final do artigo são apresentadas sugestões para novos esforços de pesquisa.
\end{abstract}

Palavras-chave: pessoas com deficiência visual; barreiras; lazer turístico.

\footnotetext{
${ }^{1}$ Mestre em Administração pela Pontifícia Universidade Católica do Rio de Janeiro (PUC-RIO); Docente da Universidade Federal do Rio de Janeiro - Instituto COPPEAD. E-mail: marinfaria86@ hotmail.com.

${ }^{2}$ Doutor em Administração pela University of Kansas, Estados Unido. Docente da Pontifícia Universidade Católica - PUC/Rio. E-mail: pcmotta@iag.puc-rio.br.
} 


\begin{abstract}
This research aimed to identify the factors that restrict the consumption of leisure tourism services for people with visual impairments. The inclusive tourism walking at a slow pace in Brazil, despite 24 million Brazilians are people with disabilities - of which $48 \%$ have visual impairments, focus of this study. In this study a questionnaire was designed with the help ofliterature review and interviews witheight key informants. The questionnaire contained 27 statements covering different aspects of constraint to tourism for people with visual impairments. The questionnaire was emailed to people with visual impairments, resulting in 202 valid responses. The results of this study suggest seven factors restricting the consumption of leisure tourism services for people with visual impairment: time, money, Personal Issues, Importance of the Company, attitudinal barriers, architectural barriers and Service. The major averages have been attributed to factors Importance of Service and Company. Considering the results, it is possible to suggest that the sector studied, lack of investment in training for the frontline staff are able to attend the visually impaired properly. At the end of the article are suggestions for new research efforts.
\end{abstract}

Keywords: people with visual impairments; barriers; leisure tourism.

\title{
Resumen
}

Esta investigación tuvo como objetivo identificar los factores que restringen elconsumo de servicios de turismo de ocio para personas con impedimentos visuales.El turismo inclusivo caminar a un ritmo lento en Brasil, a pesar de 24 millones de brasileños son las personas con discapacidad-de los cuales $48 \%$ tienendiscapacidad visual, el foco de este estudio. En este estudio se diseñó un cuestionario con la ayuda de revisión de la literatura y entrevistas con ochoinformantes clave. El cuestionario constaba de 27 estados que abarcan distintos aspectos de la restricción de turismo para personas con impedimentos visuales. El cuestionario fue enviado por correo electrónico a las personas con discapacidad visual, lo que resulta en 202 respuestas válidas. Los resultados de este estudio sugieren siete factores que restringen el consumo de servicios de turismo de ociopara personas con discapacidad visual: tiempo, dinero, problemas personales,importancia de la empresa, las barreras mentales, las barreras arquitectónicas y de servicios. Los promedios principales se han atribuido a factores de importancia del servicio y la empresa. Teniendo en cuenta los resultados, es posible sugerir que el sector estudiado, la falta de inversión en formación para elpersonal de primera líneason capaces de asistir a los discapacitados visuales correctamente. Al final del artículo se ofrecen sugerencias para nuevos estudios.

Palabras clave: personas con discapacidad visual; barreras; ocio y tiempo libre Turism. 


\section{Introdução}

Mesmo que discretamente, ao longo das últimas duas décadas, pesquisadores da área de Marketing - primordialmente acadêmicos estrangeiros - parecem ter despertado para a importância de se investigar segmentos de mercado comumente marginalizados e/ou excluídos dos estudos tradicionalmente valorizados nos campos teórico e prático (BAKER, HOLLAND \& KAUFMAN-SCARBOROUGH, 2007; COVA \& COVA, 2002; FIRAT, DHOLAKIA \& VENKATESH, 1995; SMITH \& FITCHETT, 2002; WOODLIFFE, 2004). Possibilidades relevantes de estudos abrem-se quando são enfocados os consumidores com deficiências, historicamente estigmatizados e relegados à condição de invisibilidade social (SASSAKI, 2003), especialmente se forem consideradas as pessoas com deficiência visual, tidos por Amaro et al. (2008) como desprivilegiados em termos de pesquisas acadêmicas, mesmo considerando somente os trabalhos voltados para os consumidores com deficiências.

Dirigindo sua preocupação para os consumidores com deficiência visual, Baker, Stephens e Hill (2002) recomendam que sejam conduzidos estudos acadêmicos nos setores de varejo e serviços para que, a partir deles, os praticantes possam operacionalizar a acessibilidade a bens e serviços para pessoas com diferentes deficiências. Para Baker (2006), impõe-se a necessidade de investigar como os consumidores com deficiência visual constroem suas identidades individuais e coletivas por meio dos processos de compra e consumo. McKercher et al. (2003) defendem a realização de mais pesquisas envolvendo o consumo de serviços de turismo por deficientes visuais, haja vista ser este um campo raramente explorado. Amaro et al. (2008), que estudaram a adaptação do varejo às necessidades dos consumidores portadores de deficiência visual, demandam que sejam realizados novos esforços de pesquisa envolvendo outros contextos de consumo.

As pesquisas voltadas para serviços de lazer, por sua vez, têm sido mais freqüentes (AKEL SOBRINHO, 2006; CUNHA, BARBOSA \& KOVACS, 2008) e ultimamente vêm buscando uma aproximação mais ampla com o campo da Administração (DENCKER, 2007). Deve-se notar que o escopo de tais pesquisas abrange lazer doméstico, extra-doméstico e turístico (GOMES \& REJOWSKI, 2007), sendo o lazer turístico determinado como foco do presente trabalho.

Um importante estudo sobre consumo de lazer foi realizado por Crawford e Godbey (1987), que identificaram três barreiras principais no que tange ao consumo de serviços e atividades 
de lazer: estruturais, interpessoais, intrapessoais. As barreiras estruturais representam as restrições como fatores intervenientes entre a preferência por dado tipo de lazer e a participação do consumidor nessa atividade. Recursos financeiros, clima e horário de trabalho podem ser relacionados como exemplos de barreiras estruturais. As barreiras intrapessoais envolvem o estado psicológico das pessoas e outros atributos que interagem com as preferências de lazer mais do que entre a preferência e a participação; exemplos incluem estresse, religiosidade e atitudes dos grupos de referência. As barreiras interpessoais resultam das interações entre pessoas ou do relacionamento entre suas características individuais.

Alguns anos mais tarde, Crawford, Jackson e Godbey (1991) modificaram o modelo de 1987. Esse modelo revisado indica que a eventual participação em determinado serviço ou atividade de lazer depende do fato de o consumidor não encontrar restrições de cunho intrapessoal, interpessoal ou estrutural, nessa ordem. No entanto, a não participação pode derivar da atuação das restrições em qualquer nível. Certos estudos têm utilizado esse modelo de restrição ao lazer com diferentes segmentos da população brasileira, tais como idosos (DINIZ \& MOTTA, 2006) e crianças (O’GRADY, 2007). A presente pesquisa vale-se do modelo de restrições ao lazer de Crawford, Jackson \& Godbey (1991) como ponto de partida para perseguir o objetivo de identificar os fatores que mais restringem o consumo de serviços de lazer turístico pelas pessoas com deficiência visual.

Diversos estudos acadêmicos apontam o lazer turístico como oportunidade para a inclusão social de pessoas com deficiência (ALMEIDA, 2006; SASSAKI, 2003). No Brasil, porém, a despeito de mais de 24 milhões de brasileiros serem pessoas com deficiência (IBGE, 2000), o turismo inclusivo ainda caminha a passos lentos, sendo necessários investimentos em diversos aspectos (LAGES \& MARTINS, 2006). O foco em deficientes visuais justifica-se pela representatividade do segmento, $48 \%$ das pessoas com deficiência (IBGE,op, cit.).

As pessoas com deficiência enfrentam diversas barreiras para desempenhar os mais diferentes papéis na sociedade, inclusive o de consumidores, uma vez que acadêmicos e praticantes no Brasil parecem desconsiderar esse enorme mercado (CARVALHO, 2007; LAGES \& MARTINS, 2006). Tal posição distanciada parece ser mantida mesmo nos campos de conhecimento e atuação naturalmente afeitos ao cuidado com pessoas com deficiência, 
notadamente a gestão de empresas prestadoras de serviços de turismo, lazer, entretenimento e hospitalidade (KAUFMAN-SCARBOROUGH, 1998; WOODLIFE, 2004).

O presente artigo foi estruturado em quatro seções, além desta introdução. A primeira seção apresenta o quadro teórico referencial. Na segunda seção mostra-se o método seguido para a realização da etapa empírica da pesquisa, para que na terceira seção do texto sejam detalhados os resultados do estudo. A última seção traz as considerações conclusivas e indica sugestões para futuras pesquisas.

\section{Revisão de Literatura}

\subsection{Serviços de lazer turístico}

Serviço é um desempenho oferecido por uma parte à outra, no qual o processo pode estar ligado a um produto físico, mas se faz presente um ato essencialmente intangível e que, normalmente, não resulta em propriedade de nenhum dos fatores de produção (LOVELOCK \& WRIGHT, 2003). De acordo com Zeithaml e Bitner (2003), as atividades relacionadas a turismo, lazer, entretenimento e transporte podem ser classificadas como indústrias pertencentes ao setor de serviços. Essa classificação será seguida na presente pesquisa.

A despeito do crescente interesse em ter o lazer como objeto de estudo, ainda existem muitos pontos essenciais não esclarecidos (KACZYNSKI, MANNELL \& MANSKE, 2008). Uma das confusões mais comuns é tomar lazer e turismo por sinônimos, embora nem tudo o que pode ser classificado como turismo compreende lazer e vice-versa. Ainda que alguns autores tentem sobrepor um fenômeno ao outro, deve-se notar que ambos se recortam mutuamente, possuindo um núcleo comum, mas conservando partes autônomas (CAMARGO, 2001). Muitos autores divergem no que tange às definições de lazer e o turismo. Pode-se definir turismo como o deslocamento de pessoas de seu local de residência por períodos determinados e não motivados por razões constantes de exercício profissional (IGNARRA, 2003).

O turismo não se reduz ao lazer, pois há outras motivações que não o lazer para que exista o turismo; para Gomes e Rejowski (2007), pode-se falar em turismo de lazer, de negócios e religioso. Tempo de lazer refere-se ao tempo liberado de trabalho ou de qualquer atividade 
obrigatória (MARCELINO, 2006). Para muitos autores, o lazer é formado por três pilares: o lazer doméstico, o lazer extra-doméstico (realizado na própria cidade onde reside o sujeito) e o lazer turístico, em que o sujeito se desloca de cidade para cumprir a atividade de lazer. A presente pesquisa tem seu foco no lazer turístico, que engloba atividades em tempo liberado de trabalho que não são vividas no local de residência do indivíduo (GOMES, 2004).

As pesquisas sobre restrições ao lazer vêm aumentando seu escopo e se sofisticando desde o início dos anos 1980 (JACKSON, 1991). A Figura 1 ilustra o modelo de Crawford e Godbey (1987), que lista como principais barreiras no que tange ao consumo de atividades de lazer as barreiras estruturais, interpessoais e intrapessoais. No modelo, a influência das restrições estruturais ocorre entre a preferência e a participação, ou seja, a preferência com relação aos serviços de lazer é formada, mas se existirem restrições estruturais e elas não forem superadas, a participação não ocorrerá. As barreiras intrapessoais, por sua vez, quando existem e não são superadas, impedem até mesmo a formação de preferência. As influências das restrições interpessoais ocorrem tanto na preferência quanto na participação. Segundo esse modelo os três tipos de restrição ao lazer atuam de forma independente e desconectada.
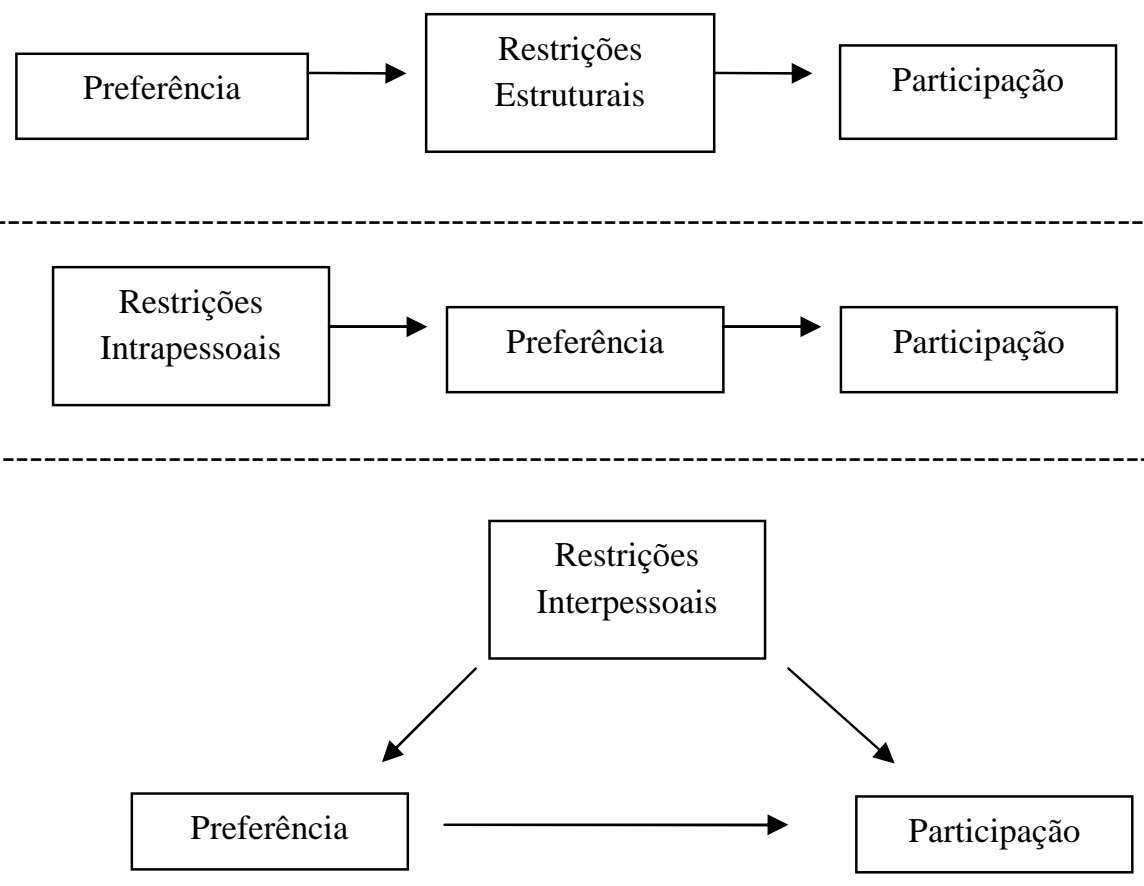

Figura 1 - Modelo de restrições de Crawford e Godbey (1987)

Fonte: Crawford e Godbey (1987) 
O modelo de Crawford, Jackson e Godbey (1991) aborda o processo dinâmico de como as pessoas negociam suas restrições ao lazer. Nesse modelo, as preferências de lazer são formadas quando as restrições intrapessoais estão ausentes ou já foram confrontadas com sucesso. O indivíduo pode então encontrar restrições no nível interpessoal, se na atividade de lazer for requerido ao menos um co-participante. As restrições estruturais começam a ser consideradas somente quando são ultrapassadas as restrições interpessoais, caso existam. A participação resultará da ausência ou negociação de sucesso das restrições estruturais; se forem suficientemente fortes. Contudo, o resultado será a não participação na atividade.

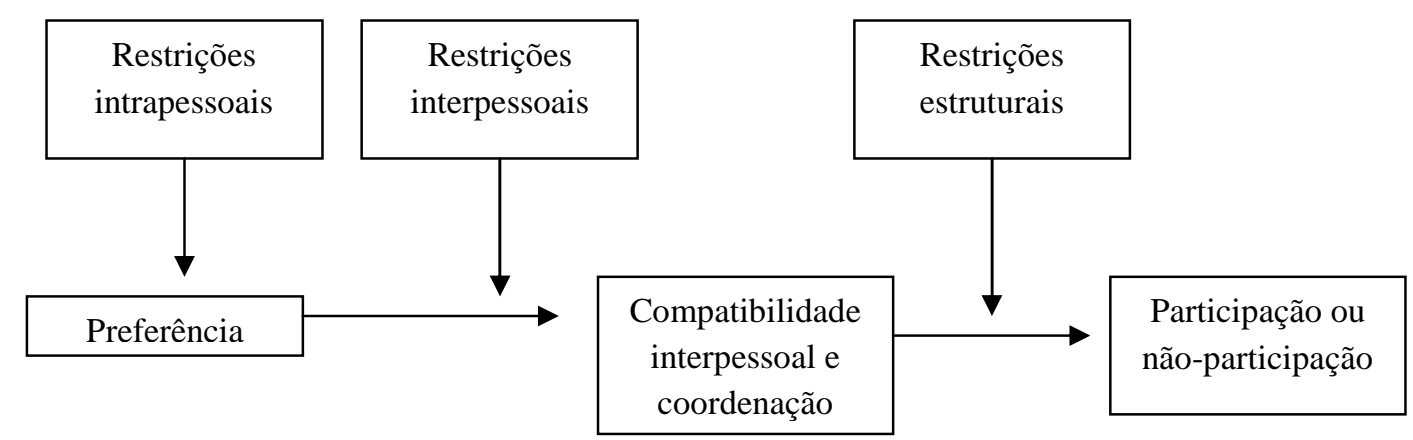

Figura 2 - O modelo hierárquico de restrições de Crawford, Jackson e Godbey (1991) Fonte: Crawford, Jackson e Godbey (1991)

De acordo com a literatura, pessoas com melhor educação e maior renda estão sujeitas a menos (ou mais fracas) restrições intrapessoais e interpessoais (CRAWFORD, JACKSON e GODBEY, op. cit.; JACKSON, 1990). No que diz respeito a gênero, o estudo de Raymore et al. (1994) sugere que as mulheres têm uma maior percepção de restrições intrapessoais, tais como timidez, falta de habilidades e falta de conhecimento das oportunidades existentes. Alguns autores contestaram a ideia de que as restrições ao lazer necessariamente restringem ou impedem a participação em atividades de lazer. Para eles, as ameaças à participação em atividades de lazer podem ser na maioria das vezes superadas (KAY \& JACKSON, 1991). 
A despeito de a Constituição Federal Brasileira de 1988 reconhecer o lazer como direito social, Ladislau (2002) afirma que a ausência de uma política de desenvolvimento urbano que priorize o acesso dos cidadãos aos espaços de lazer contribui para a restrição do lazer para uma parcela da população. Desse modo, pensar num desenvolvimento do lazer para todos requer pensar em saídas eficazes para permitir a efetiva participação no processo.

\subsection{Pessoas com deficiências: cidadãos e consumidores}

Não existe consenso entre os autores que focam seus estudos em pessoas com deficiência nem mesmo no que diz respeito a como denominar seus sujeitos de pesquisa (COUTINHO \& CARVALHO, 2007). O termo "portadores de necessidades especiais" é muito utilizado; devese notar, contudo, que tal expressão refere-se a qualquer pessoa que, permanente ou temporariamente, apresenta necessidades especiais em decorrência de sua condição atípica. Assim, esse termo pode abranger, por exemplo, gestantes, idosos, cadeirantes e deficientes mentais (GOULART, 2007). A maioria dos autores parece privilegiar o termo "pessoas portadoras de deficiência“, ainda que alguns optem por utilizar "pessoas com deficiência", em razão de considerar que as deficiências de um ser humano não são portadas, mas antes são vivenciadas pelas pessoas (CARVALHO, 2007). No presente trabalho, esses termos são utilizados como sinônimos, com o objetivo de facilitar o entendimento do texto.

Outra divergência bastante recorrente acontece quando se pretende definir quem entra ou não na classificação de deficiente. Tais diferenças nos parâmetros de classificação acabam dificultando a comparação do número de deficientes por país, por exemplo, haja vista que cada país utiliza um conceito próprio (MBOGGONI \& SYNNEBORN, 2009). No Brasil, o número de pessoas com deficiências divulgado pelo IBGE é contabilizado por autodeclaração.

Os dados do último censo do IBGE (2000) revelam que 14,5\% da população brasileira - o que corresponde a 24,5 milhões de pessoas - apresentam algum tipo de deficiência. Desses indivíduos, 19,8 milhões residem em zonas urbanas. O Sudeste é a região com a menor proporção de pessoas com deficiência $(13,1 \%)$, enquanto o Nordeste apresenta o maior percentual (16,8\%). A Tabela 1, mostrada a seguir, traz dados do censo abertos por deficiência e sexo. Na análise da tabela deve-se notar que o censo indica um número maior de 
deficiências do que de pessoas com deficiência, em função de os indivíduos com deficiências múltiplas (aproximadamente 10 milhões de pessoas) serem contados mais de uma vez.

Tabela 1 - Tipos de deficiências por gênero

\begin{tabular}{l|l|l|l|l|l|l}
\hline Tipo de Deficiência & Visual & Motora & Auditiva & Mental & Física & Total \\
\hline Homens & 7.259 .074 & 3.295 .071 & 3.018 .218 & 1.545 .462 & 861.196 & 15.979 .021 \\
\hline Mulheres & 9.385 .768 & 4.644 .713 & 2.716 .881 & 1.299 .474 & 554.864 & 18.601 .700 \\
\hline Total & 16.644 .842 & 7.939 .784 & 5.735 .099 & 2.844 .936 & 1.416 .060 & 34.580 .721 \\
\hline
\end{tabular}

Fonte: Censo do IBGE (2000)

Profissionais da saúde chamam atenção para o fato de que uma das causas do crescimento do número de deficientes em todo o mundo é o avanço da tecnologia e, consequentemente, das práticas médicas. Com o desenvolvimento das ciências da saúde, muitas pessoas que naturalmente morreriam são salvas, ainda que sejam levadas a apresentar sequelas irreversíveis (BAKER, HOLLAND \& KAUFMAN-SCARBOROUGH, 2007).

A despeito de ainda enfrentarem inúmeros problemas, as pessoas com deficiências vêm obtendo conquistas importantes, como o direito à educação desde o ensino básico até a universidade, bem como a Lei das Cotas, que obriga empresas a partir de determinado porte a reservar parte de suas vagas para pessoas com deficiência (MEIRA, AMARO \& ALMEIDA, 2009).

O presente trabalho tem como foco pessoas com deficiência visual, as quais, beiram os 17 milhões de brasileiros, sendo 13 milhões habitantes de áreas urbanas (IBGE, 2000). A deficiência visual é caracterizada pela anulação ou pelo sério comprometimento da captação das informações ambientais pelo canal perceptivo da visão, categorizando as pessoas respectivamente em cegas ou indivíduos com baixa visão (POYARES \& GOLDFELD, 2008).

Registram-se poucos estudos em Administração no Brasil com enfoque em pessoas com deficiências visuais, sendo a maioria na área de Recursos Humanos, frequentemente denotando a preocupação com a inclusão de tais indivíduos no mercado formal de trabalho. Silva (2007), por exemplo, mostrou que o aproveitamento das pessoas com deficiência visual 
como força de trabalho ainda enfrenta muita resistência, principalmente pelo fato de as empresas desconhecerem as tarefas que essas pessoas podem desempenhar.

Por outro lado, alguns estudos em Administração têm traduzido a preocupação com a acessibilidade para pessoas com deficiência visual no que tange ao acesso a meios de informação, principalmente a internet, mostrando que, apesar das mudanças nos últimos anos, ainda não existe acessibilidade (BACH, FERREIRA \& SILVEIRA, 2009; FERREIRA, CHAUVEL \& FERREIRA, 2007). Como a visão passou a ser o principal meio sensório com o qual se pode interagir com os sistemas de internet, não importa quão bem projetada seja uma interface, ela jamais estará em consonância com o modelo conceitual dos usuários cegos (JACKO et al., 1999).

No que diz respeito à inclusão das pessoas com deficiência visual como consumidores, as pesquisas em Marketing basicamente se restringem às contribuições estrangeiras, com raras exceções no Brasil. Amaro et al. (2008, p. 1), por exemplo, mostraram que os varejistas brasileiros vêm se preocupando mais com os consumidores com dificuldades de mobilidade, enquanto os deficientes visuais encontram-se desamparados para comprar, fazendo com que eles possam ser caracterizados como uma "parcela de consumidores normalmente esquecida". Baker (2006) alerta para a importância de que os funcionários de contato no varejo recebam treinamento para lidar com as diferentes necessidades das pessoas com deficiências, alertando para o fato de que o atendimento é tão importante quanto adaptações físicas no ambiente. Para Baker, Stephens e Hill (2002), a segmentação de mercado em consumidores deficientes versus não-deficientes é ingênua: algumas mudanças arquitetônicas em um ambiente podem ser apropriadas para um cliente com dificuldades de locomoção, mas podem não afetar em nada a acessibilidade do ambiente para um indivíduo com deficiência visual.

Ainda que as pessoas com deficiência continuem enfrentando muitas barreiras em situações de consumo de bens e serviços, registra-se um avanço nas discussões acerca da inclusão social e da melhoria da qualidade de vida dessas pessoas. O lazer turístico, por instância, surge como potencial motivador da inclusão social, visando à ampliação da participação de todos na atividade do turismo (MENDES \& NILMA, 2008). 


\subsection{Lazer e turismo para pessoas com deficiência}

Ainda que de maneira rudimentar, na década de 1970 surgiram as primeiras excursões organizadas por agências de viagem para pessoas deficientes. Apenas na década de 1980, acompanhando o movimento pela integração social, é que o problema das viagens começou a ganhar espaço e novas discussões acerca do tema começaram a surgir. O lazer turístico passou a ser apontado como oportunidade para possibilitar a inclusão social de pessoas com deficiência (SASSAKI, 2003). Nesse sentido, observa-se atualmente uma tendência de democratização dos serviços turísticos (ALMEIDA, 2006).

De acordo com Sassaki (op. cit.) as barreiras mais comuns encontradas pelos deficientes nos logradouros de lazer são atitudinais, comunicacionais e arquitetônicas. As duas primeiras têm forte ligação com a falta de preparo dos atendentes, em virtude, por exemplo, de a maioria dos funcionários de hotéis e restaurantes não ter qualquer tipo de competência para atender pessoas com deficiência (BAKER, 2006; SCHIVITZ, 2007). Quando o olhar se volta para o deficiente auditivo, por exemplo, as barreiras comunicacionais são muito fortes, ensejando preocupações em razão da absoluta falta de pessoal qualificado para o atendimento a tais clientes. Na pesquisa de Costa (2006), não se encontrou em nenhum hotel da cidade de Belo Horizonte alguém que conhecesse LIBRAS - a Língua Brasileira de Sinais.

As barreiras arquitetônicas estão mais presentes nas vidas dos cadeirantes e outras pessoas com deficiências motoras. $\mathrm{O}$ aspecto mais recorrente é a falta de rampas e de banheiros adaptados (SASSAKI, 2003). Para Burnett (1996) e Castell (2008), assim como para Upchurch e Seo (1996), o problema das instalações físicas é o mais comum no que se refere ao impedimento de um deficiente exercer plenamente o papel de consumidor. Como resposta a essa questão, Gilmore e Rentschler (2002) recomendam que os museus utilizem a expertise desenvolvida em marketing e ofereçam instalações físicas e serviços de hospitalidade capazes de melhorar a experiência dos deficientes com o ambiente do serviço. Burnett (op. cit.) estende tais recomendações para quaisquer ambientes físicos de serviços.

No que tange à hotelaria, é importante que todas as áreas do hotel - tais como piscinas, restaurantes e quadras esportivas - sejam acessíveis às pessoas com deficiência (GOULART, 2007). Para Soubeniotis et al. (2007), os hotéis de luxo transmitem a imagem de que são 
capazes de fornecer serviços adequados quando em seus esforços de comunicação de marketing, além de outros fatores, está incluída a preocupação com indivíduos com deficiências físicas e/ou mentais. Por outro lado, algumas vezes essa imagem pode não corresponder à realidade, como aponta o trabalho de Sansivieiro e Dias (2005), que mostra sérios problemas de acessibilidade para deficientes em hotéis de luxo da cidade de São Paulo.

Raposo e López (2002) estudaram serviços de lazer voltados para pessoas com lesões medulares; os resultados apontam que essas pessoas têm muita necessidade de lazer, mas em virtude da falta de opções, acabam se contentando com alternativas simples. Muitas pessoas com deficiência não sabem que podem existir opções de lazer acessíveis, fazendo com que se conformem as limitações e abram mão do lazer (BURNETT,1996; RUDDELL \& SHINEW, 2006).

A falta de opção de lazer também se faz presente quando se trata de crianças com deficiências. Knight (2009) denuncia a ausência de alternativas direcionadas a elas, defendendo que deveriam ser adotar medidas imediatas para melhorar tal situação, pois a falta de lazer aumenta o isolamento social dessas crianças. Heikkilä et al. (1999) e Woodliffe (2004) alertam para o fato de que consumidores idosos ou com problemas de saúde enfrentam desvantagens semelhantes no que se refere ao pleno aproveitamento da vida em sociedade.

Chegar aos locais escolhidos para o lazer já constitui um grande problema. Faltam ônibus adaptados e as barreiras de acessibilidade surgem até mesmo em viagens aéreas (BURNETT, 1996; BURNETT \& BAKER, 2001; KAUFMAN, 1995). Darcy (2009) estudou as práticas das companhias aéreas para o atendimento às pessoas com deficiência e apontou que são necessárias muitas mudanças, principalmente nos momentos do embarque e do desembarque.

Investigando o consumo de serviços de lazer turístico por pessoas com deficiência motora, Ray e Ryder (2003) apontaram que na busca por informações de viagem - bem como no planejamento da viagem - tais consumidores costumam contar com amigos, com a ajuda da internet e com os serviços de agentes de viagens. Daniels, Rodgers e Wiggins (2005), a seu turno, argumentam que as agências de turismo que se preocupam com a inclusão de pessoas com deficiência no planejamento de suas viagens podem melhorar o serviço oferecido para todos os viajantes. O cenário atual, entretanto, indica que as agências não tem tido essa 
preocupação: poucas criam pacotes para as pessoas com deficiência (NASCIMENTO et al., 2008).

A EMBRATUR criou um manual de acessibilidade para as pessoas com deficiências (ver: Manual, 2010), em que se define acessibilidade como possibilidade e condição do portador de deficiência utilizar, com segurança e autonomia, edificações e equipamentos de interesse turístico. Outra iniciativa com o mesmo objetivo foi um guia lançado em outubro de 2001, em São Paulo, dedicado à avaliação da acessibilidade da cidade para as pessoas com mobilidade reduzida, o "Guia São Paulo Adaptada" (SANVIEIRO \& DIAS, 2005). Tais iniciativas, contudo, não são suficientes para garantir às pessoas com deficiência acesso ao lazer nas cidades brasileiras; como foi sugerido por Yau, McKercher e Packet (2004), pois parece faltar principalmente o treinamento para que as pessoas possam atender a esse público.

\section{Método}

O modelo de restrição ao lazer desenvolvido por Crawford, Jackson, \& Godbey (1991) é utilizado nesse estudo para a análise dos principais fatores que restringem o consumo de serviços de lazer turístico para deficientes visuais. Anteriormente, valendo-se desse modelo, Daniels, Rodgers e Wiggins (2005) identificaram que os deficientes tendem a enfrentar problemas de ordem interpessoal, intrapessoal e estrutural fortes e de difícil resolução.

\subsection{Amostra}

A amostra da pesquisa foi constituída por critérios não probabilísticos, por conveniência e acessibilidade (VERGARA, 2009), e contou com um total de 218 pessoas com deficiência visual. Os questionários que continham missing values foram eliminados (HAIR et al., 2006), o que fez com que o número de questionários válidos fosse igual a 202. A Tabela 2 resume algumas características da amostra. 
Tabela 2 - Caracterização da amostra por gênero, faixa etária e renda

\begin{tabular}{|c|c|c|c|c|c|}
\hline Gênero & Ocorrências & $\%$ & & & \\
\hline Feminino & 103 & $51 \%$ & & & \\
\hline Masculino & 99 & $49 \%$ & & & \\
\hline Faixa etária & Ocorrências & $\%$ & Renda & Ocorrências & $\%$ \\
\hline até 25 anos & 19 & $9 \%$ & até $\mathrm{R} \$ 2.000$ & 89 & $44 \%$ \\
\hline de 26 a 40 anos & 56 & $28 \%$ & de $R \$ 2.001$ a $R \$ 5.000$ & 61 & $30 \%$ \\
\hline de 41 a 55 anos & 49 & $24 \%$ & de $\mathrm{R} \$ 5.001$ a $\mathrm{R} \$ 10.000$ & 38 & $19 \%$ \\
\hline Acima de 55 anos & 78 & $39 \%$ & acima de $\mathrm{R} \$ 10.000$ & 14 & $7 \%$ \\
\hline
\end{tabular}

\subsection{Coleta de dados}

O questionário utilizado na pesquisa foi elaborado com base na revisão da literatura e em oito entrevistas pessoais com informantes-chaves selecionados por seu potencial em contribuir para a compreensão do fenômeno (COOPER \& SCHINDLER, 2003; YIN, 2004). A validade e a confiabilidade do protocolo de utilização de múltiplos informantes-chaves foram atestadas por John e Reve (1982), por Svensson (2006) e por Hemmington e King (2000), sendo que estes últimos valeram-se da técnica para a pesquisa de serviços de hotelaria.

A escolha dos 8 informantes-chaves privilegiou indivíduos que atendessem a pelo menos dois dentre os seguintes critérios: a) pessoas que tivessem contato sistemático com portadores de deficiência visual há pelo menos cinco anos; b) pessoas que tivessem contato direto com um grande número de pessoas com deficiência visual; e (c) pessoas com conhecimento da vivência de situações de lazer por portadores de deficiência visual. Apenas três dentre os 8 informantes eram deficientes. As interações com os informantes podem ser classificadas como entrevistas focalizadas, semi-estruturadas e não padronizadas (GIL, 2008, 2009; KERLINGER \& LEE, 2000). A Tabela 3 sintetiza as principais qualificações dos informantes, dos quais se optou por preservar os nomes, sendo sua identificação codificada a partir de I-01 (primeira informante) até I-8 (décimo-primeiro informante). 
Tabela 3- Informantes da pesquisa e suas principais qualificações

\begin{tabular}{c|l}
\hline Informante & Qualificação \\
\hline I-01 & cocriadora da maior comunidade de pessoas com deficiências no site de relacionamentos Orkut \\
\hline I-02 & cocriadora da maior comunidade de pessoas com deficiências no site de relacionamentos Orkut \\
\hline I-03 & deficiente visual/professora do Instituto Benjamin Constant \\
\hline I-04 & membro da Rede Interamericana de Turismo Acessível / co-criador da ONG Turismo Adaptado \\
\hline I-05 & $\begin{array}{l}\text { profissional de recursos humanos voltada para a inclusão de pessoas com deficiência no mercado } \\
\text { de trabalho }\end{array}$ \\
\hline I-06 & coordenadora do curso de graduação em Turismo de uma IFES localizada no Rio de Janeiro \\
\hline I-07 & Ex-diretora da Associação dos Pais e Amigos de Excepcionais (APAE) de Porto Alegre \\
\hline I-08 & Ex-presidente da Associação dos Pais e Amigos de Excepcionais (APAE)de Porto Alegre \\
\hline
\end{tabular}

Em consonância com as ideias de Dencker (2007) acerca de pesquisas no campo de Turismo, utilizou-se um questionário, que na presente pesquisa contou com 27 assertivas, cobrindo diversos aspectos de restrição ao turismo para pessoas com deficiência visual. As assertivas tinham como propósito a avaliação da seguinte proposta de lazer turístico, extraída da pesquisa de Diniz e Motta (2006, p. 6) sobre restrições a lazer para pessoas de mais idade e adaptada de acordo com os resultados obtidos nas entrevistas com os informantes-chaves:

Suponha que tenha sido oferecida a você uma viagem de 15 dias para o litoral sul do país. A viagem cobrirá 3 estados da região e terá início daqui a 30 dias. Você irá e voltará de avião, mas o transporte entre cidades será feito de ônibus e você ficará hospedado em hotéis com amplas áreas de lazer. As viagens de ônibus não terão duração superior a 3 horas, porém, haverá um dia em que você fará 2 viagens de ônibus de 3 horas cada uma. Haverá alguns passeios de barco. O custo total da excursão é estimado em R \$ 3.000,00 já incluindo despesas pessoais básicas.

As assertivas foram elaboradas com o auxílio dos resultados obtidos nas entrevistas com os informantes-chaves. As assertivas "Não iria a essa excursão por ter medo que os comissários e outras pessoas da companhia aérea não estivessem preparados para me auxiliar" e "Não iria a essa excursão por ter medo que os atendentes do hotel não estivessem preparados para me auxiliar por não saberem lidar com pessoas deficientes", por exemplo, emergiram das entrevistas com os informantes I-4 e I-6. 
Para a avaliação das assertivas foi utilizada uma escala Likert de 5 pontos variando de 1 (discordo totalmente) a 5 (concordo totalmente). Também foram incluídas perguntas de caráter sociodemográfico, tais como gênero, idade e renda mensal familiar. O questionário foi enviado via internet (GIL, 2008) por ter sido considerado que esse era o modo mais fácil de conseguir atingir as pessoas com deficiência, principalmente aquelas com deficiência visual que utilizam softwares especiais de leitura de texto no computador. O questionário foi prétestado com 10 pessoas com deficiência visual. Para atingir um número maior de respostas, o questionário foi enviado para grupos de email de pessoas com deficiência visual. A amostra final da pesquisa foi composta por 202 pessoas com deficiência visual.

\subsection{Tratamento dos dados}

Seguindo o caminho de estudos anteriores que também focaram em restrições ao turismo (ALEXANDRIS \& CARROL, 1997; DINIZ \& MOTTA, 2006; PENNINGTON-GRAY \& KERTETTER, 2002) o tratamento dos dados foi feito por meio de análise de fatores com a utilização do software estatístico SPSS versão 17. O objetivo da análise de fatores é encontrar um meio de condensar a informação contida em um número de variáveis originais em um conjunto menor de variáveis estatística (fatores) com perda mínima de informação (HAIR et al., 2006). Na presente pesquisa a análise fatorial foi feita para condensar as informações sobre as restrições ao lazer para as pessoas com deficiência visual formando fatores que podem representar as restrições mais importantes para essas pessoas.

\section{Análise dos Resultados}

Como resultado da análise fatorial foram encontrados sete fatores: Tempo, Recursos Financeiros, Questões Pessoais, Importância da Companhia, Barreiras Atitudinais, Barreiras Arquitetônicas e Atendimento. Alguns desses fatores já haviam aparecido nas entrevistas com informantes-chaves. Analisando os fatores formados, percebeu-se que os fatores Tempo e Recursos Financeiros, ambos classificados como estruturais de acordo com o modelo de restrição ao lazer de Crawford, Jackson \& Godbey (1991), são apontados pela literatura em lazer como importantes restrições ao lazer independentemente do segmento de consumidores que esteja sendo considerado (BAHL, 2003; DINIZ \& MOTTA, 2006). 
Os fatores Questões Pessoais e Importância da Companhia apareceram, ainda que caracterizados de forma um pouco diferente, em estudo anterior que utilizou o modelo de restrições ao lazer de Crawford, Jackson \& Godbey (1991) para pessoas idosas (DINIZ \& MOTTA, 2006). Adicionalmente, vale notar que outros fatores encontrados na presente pesquisa aparecem na literatura como barreiras que dificultam o consumo de serviços de lazer para as pessoas com deficiências. Esses fatores são Atendimento (BAKER, 2006), Barreiras Atitudinais e Barreiras Arquitetônicas (CASTELL, 2008; SASSAKI, 2003).

A Tabela 4 traz os fatores encontrados na presente pesquisa. Os números que precedem as assertivas são as cargas de fatores, selecionadas por valores superiores a 0,50. Duas assertivas foram eliminadas por não alcançar 0,50 de comunalidade. Foram calculadas as médias aritméticas para cada assertiva com o objetivo de verificar que fatores seriam mais restritivos para pessoas com deficiência visual no consumo de serviços de lazer turístico.

Tabela 4 - Fatores de restrição ao lazer encontrados na pesquisa

\begin{tabular}{|c|c|c|c|}
\hline Fator & Assertivas & $\begin{array}{l}\text { Média } \\
\text { geral }\end{array}$ & Classificação \\
\hline Tempo & $\begin{array}{l}\text { [ 0,86] Não posso ficar tanto tempo longe de casa. } \\
{[0,73] \text { Tenho ocupações que me impedem de fazer essa excursão. }} \\
\text { [ 0,67] } 30 \text { dias é muito pouco tempo para planejar essa viagem. }\end{array}$ & $\begin{array}{l}1,83 \\
1,76 \\
1,67\end{array}$ & Estrutural \\
\hline $\begin{array}{c}\text { Recursos } \\
\text { Financeiros }\end{array}$ & $\begin{array}{l}\text { [0,82] Não tenho condições financeiras para fazer uma excursão } \\
\text { como essa. } \\
{[0,78] \text { Se essa excursão fosse mais barata, talvez eu pudesse }} \\
\text { viajar. }\end{array}$ & $\begin{array}{l}1,72 \\
1,91\end{array}$ & Estrutural \\
\hline Questões & $\begin{array}{l}\text { [0,64] Não faria essa excursão porque não gosto de viajar } \\
\text { [0,67] Não faria essa excursão porque não tenho o costume de } \\
\text { viajar } \\
\text { [0,86] Não me sinto preparado para fazer essa excursão por causa } \\
\text { das necessidades especiais que eu tenho } \\
\text { [-0,65] Tenho sempre vontade de fazer uma excursão como essa. } \\
{[0,70] \text { Tenho medo de ir a essa excursão e não gostar. }}\end{array}$ & $\begin{array}{l}1,34 \\
2,45 \\
3,22 \\
1,32\end{array}$ & Intrapessoal \\
\hline
\end{tabular}




\begin{tabular}{|c|c|c|c|}
\hline $\begin{array}{c}\text { Importância da } \\
\text { companhia }\end{array}$ & $\begin{array}{l}{[0,81] \text { Acho mais importante a pessoa ou pessoas que vão comigo }} \\
\text { na excursão do que o local escolhido para viajar } \\
{[0,87] \text { Minha maior dificuldade para fazer uma excursão é não }} \\
\text { ter companhia. } \\
{[0,57] \text { As pessoas que poderiam ir comigo não têm tempo. }} \\
{[0,61] \text { Prefiro viajar em excursões do que viajar por conta própria. }} \\
{[0,83] \text { Preciso viajar sempre acompanhado. }}\end{array}$ & $\begin{array}{l}3,63 \\
3,13 \\
2,33 \\
4,16\end{array}$ & Interpessoal \\
\hline $\begin{array}{l}\text { Barreira } \\
\text { atitudinais }\end{array}$ & $\begin{array}{l}\text { [-0,84] Penso que as pessoas das minhas relações me } \\
\text { incentivariam a fazer essa excursão } \\
{[0,85] \text { Penso que as pessoas das minhas relações acham que uma }} \\
\text { excursão como essa não é apropriada para mim. } \\
\text { [0,88] Não iria a essa excursão por ter medo que as outras pessoas } \\
\text { de excursão não soubessem entender e respeitar as minhas } \\
\text { limitações físicas. }\end{array}$ & $\begin{array}{l}1,32 \\
2,21 \\
2,86\end{array}$ & Interpessoal \\
\hline Atendimento & $\begin{array}{l}\text { [0,84] Não iria a essa excursão por ter medo que os comissários e } \\
\text { outras pessoas da companhia aérea não estivessem preparados para } \\
\text { me auxiliar. } \\
{[0,89] \text { Não iria a essa excursão por ter medo que os atendentes do }} \\
\text { hotel não estivessem preparados para me auxiliar. Por não saberem } \\
\text { lidar com pessoas deficientes. }\end{array}$ & 4,04 & Interpessoal \\
\hline $\begin{array}{c}\text { Barreiras } \\
\text { arquitetônicas }\end{array}$ & $\begin{array}{l}\text { [0,72] Não iria a essa excursão por ter medo que o avião não } \\
\text { estivesse fisicamente adaptado para atender as minhas } \\
\text { necessidades. } \\
\text { [0,76] Não iria a essa excursão por ter medo que o ônibus não } \\
\text { estivesse fisicamente adaptado para atender as minhas } \\
\text { necessidades. } \\
\text { [0,80]Não iria a essa excursão por ter medo que o quarto do hotel } \\
\text { não estivesse fisicamente adaptado para atender as minhas } \\
\text { necessidades. } \\
\text { [0,81]Não iria a essa excursão por ter medo que a área de lazer do } \\
\text { hotel não estivesse fisicamente adaptada para atender as minhas } \\
\text { necessidades. } \\
\text { [0,79] Não iria a essa excursão por ter medo que os locais dos } \\
\text { passeios não estivessem fisicamente adaptados para atender as } \\
\text { minhas necessidades. }\end{array}$ & 2,29 & Estrutural \\
\hline
\end{tabular}


Pela análise das médias foi possível verificar que as assertivas aparentemente mais importantes no que tange à restrição ao lazer para pessoas com deficiência visual são as que compõem os fatores Atendimento e Importância da Companhia, ambos classificados como interpessoais, de acordo com o modelo hierárquico de restrições ao lazer (CRAWFORD, JACKSON \& GODBEY, 1991). A assertiva que apresentou a maior média foi "Preciso viajar sempre acompanhado" que compõe o fator Importância da Companhia; vale notar que os informantes I-1, I-2 e I-8 apontaram essa assertiva como a mais realista. Esse resultado parece indicar que não existir acessibilidade nos locais e ambientes de serviços de lazer turístico, pois a acessibilidade pressupõe que as pessoas com deficiência tenham autonomia.

A assertiva "Prefiro viajar em excursões do que viajar por conta própria" apresentou a menor média entre as assertivas que compõem o fator Importância da Companhia. Esse resultado talvez confronte a posição de McKercher et al. (2003), que acreditam que os pacotes turísticos constituam a melhor opção para os consumidores com deficiência visual, em função de serem mais baratos e mais fáceis de adquirir, de poderem ser melhor planejados e de favorecerem o encontro com pessoas com as quais o consumidor possa se socializar.

Barreiras interpessoais são apontadas pela literatura como muito prejudiciais para o consumo de serviços de lazer pelas pessoas com deficiência. Mais especificamente, os teóricos apontam como um dos principais problemas a falta de treinamento dos funcionários que têm que lidar com as pessoas com deficiência na prestação do serviço de lazer (BAKER, 2006; SCHIVITZ, 2007). A presente pesquisa confirma a importância de que os funcionários sejam bem treinados, já que o fator Atendimento apresentou médias muito elevadas.

O fator Barreiras Arquitetônicas, que havia sido apontado em alguns estudos acadêmicos como crítico para pessoas com deficiência motora (SASSAKI, 2003), também apresentou médias elevadas, demonstrando que as pessoas com deficiência visual sofrem também com a falta de adaptações físicas dos locais de lazer turístico. Dentro do fator Barreiras Arquitetônicas, a assertiva "Não iria a essa excursão por ter medo que a área de lazer do hotel não estivesse fisicamente adaptada para atender as minhas necessidades" apresentou a maior média. Esse resultado confirma o que a literatura apontou, mostrando que os hotéis têm que 
ser acessíveis, não apenas no que ser refere às acomodações, como também no que diz respeito ás áreas de lazer do hotel (GOULART, 2007).

As menores médias foram obtidas nas assertivas que compunham os fatores Recursos Financeiros e Tempo; ambos os fatores podem ser classificados como restrições estruturais, de acordo com o modelo de Crawford, Jackson e Godbey (1991). Esse resultado - talvez refletindo a natureza da amostra constituída para o estudo, composta por sujeitos com acesso a computador - indica que dinheiro e tempo não se apresentaram como fatores tão restritivos para o consumo de serviços de lazer por pessoas com deficiência visual, diferentemente do que se encontrou em pesquisas sobre restrição ao lazer para outros segmentos da população. Diniz e Motta (2006), por exemplo, apontaram a falta de tempo e de dinheiro como maior restrição ao lazer para pessoas idosas. Bahl (2003) também aponta a falta de tempo como um dos maiores obstáculos para o consumo de lazer para a maioria das pessoas.

As assertivas ligadas a questões intrapessoais apresentaram médias baixas. A menor média foi a da assertiva "Não faria essa excursão porque não gosto de viajar" o que parece indicar que as pessoas com deficiência visual constituem um público potencial para as empresas de lazer turístico. Aparentemente outros fatores, que não os intrapessoais, parecem dificultar que as pessoas com deficiências visuais consumam serviços de lazer.

\section{Considerações Conclusivas}

O objetivo da presente pesquisa foi identificar os fatores que mais restringem o consumo de serviços de lazer turístico pelas pessoas com deficiência visual. Seguindo o modelo de Crawford, Jackson e Godbey (1991), os resultados sugerem que as pessoas com tal deficiência parecem não ter problemas em formar preferências de lazer, uma vez que restrições intrapessoais não se mostraram muito significativas. As restrições interpessoais, por outro lado, mostraram-se muito fortes, principalmente no que diz respeito à necessidade de companhia e ao despreparo dos atendentes que prestam os serviços de lazer turístico. No que tange às restrições estruturais, somente aquelas relativas às barreiras arquitetônicas parecem ter forte influência na participação das pessoas com deficiência visual no lazer turístico. 
Pessoas com deficiência visual parecem constituir um público potencial para o consumo de serviços de lazer turístico, tanto em função de sua representatividade numérica quanto pela vontade de viajar que demonstraram ter. Outro ponto que faz com que os deficientes visuais configurem-se como potenciais consumidores de lazer turístico é o fato de essas pessoas não apresentarem restrições expressivas de tempo ou de recursos financeiros, segundo foi apurado no presente trabalho. Deve-se atentar para os argumentos de McKercher et al. (2003), para quem que o grande contingente de pessoas com deficiências visuais representa um mercado significativo a ser explorado pelas empresas ligadas ao lazer e ao turismo, especialmente quando se considera que tais consumidores costumam viajar acompanhados por amigos e/ou parentes. Aparentemente, todavia, as empresas que oferecem serviços de lazer turístico ainda não se deram conta do retorno financeiro que pode ser proporcionado por esse segmento de consumidores, os quais continuam enfrentando diversas barreiras para consumir esse tipo de serviço. A inadequação física dos ambientes de serviços de lazer para as pessoas com deficiência visual configura uma barreira importante, mas o que o presente estudo parece confirmar é que as barreiras mais difíceis são as de ordem interpessoal.

Diante dos resultados obtidos e da literatura revista, é possível sugerir que no setor estudado faltam investimentos em treinamento para que os funcionários da linha de frente estejam capacitados a atender os deficientes visuais de forma adequada. No entanto, para que essa capacitação seja efetiva é preciso que as organizações voltadas para a prestação de serviços de lazer saibam o que realmente é importante para tais consumidores. Curiosamente, pode-se especular, contudo, que as empresas não estão preocupadas em oferecer serviços de lazer turístico realmente acessíveis para as pessoas com deficiência. Algumas até investem em adaptações físicas, mas poucas levam em consideração todas as mudanças que deveriam ser feitas para que de fato os serviços de lazer turístico fossem acessíveis para as pessoas com deficiência visual. Cabe recordar que para Corrêa (2009, p. 171), "acessibilidade" é "garantir que todas as pessoas tenham acesso a todas as áreas de seu convívio (...) relacionadas aos espaços, mobiliários, equipamentos urbanos, sistemas e meios de comunicação e informação". Um forte indício de que a acessibilidade parece, por ora, distante de ser alcançada nos serviços de lazer turístico é a importância que apresentou a companhia - fator que envolve o aproveitamento dos serviços e das atividades de lazer com outras pessoas - para as pessoas 
com deficiência visual no contexto investigado. Tal importância, que foi confirmada pela presente pesquisa, revela haver ainda muita coisa a ser modificada, uma vez que as pessoas com deficiência visual parecem não ter autonomia para consumir serviços de lazer, como se poderia pressupor pelo conceito de acessibilidade.

Acredita-se que a principal contribuição para teóricos e praticantes apresentada pela presente pesquisa seria a possível complementação e adaptação do modelo de Crawford, Jackson e Godbey (1991) para pessoas com deficiência visual. A Figura 3 apresenta esse modelo que poderá auxiliar no entendimento das restrições aos serviços de lazer turístico para as pessoas com deficiência visual.

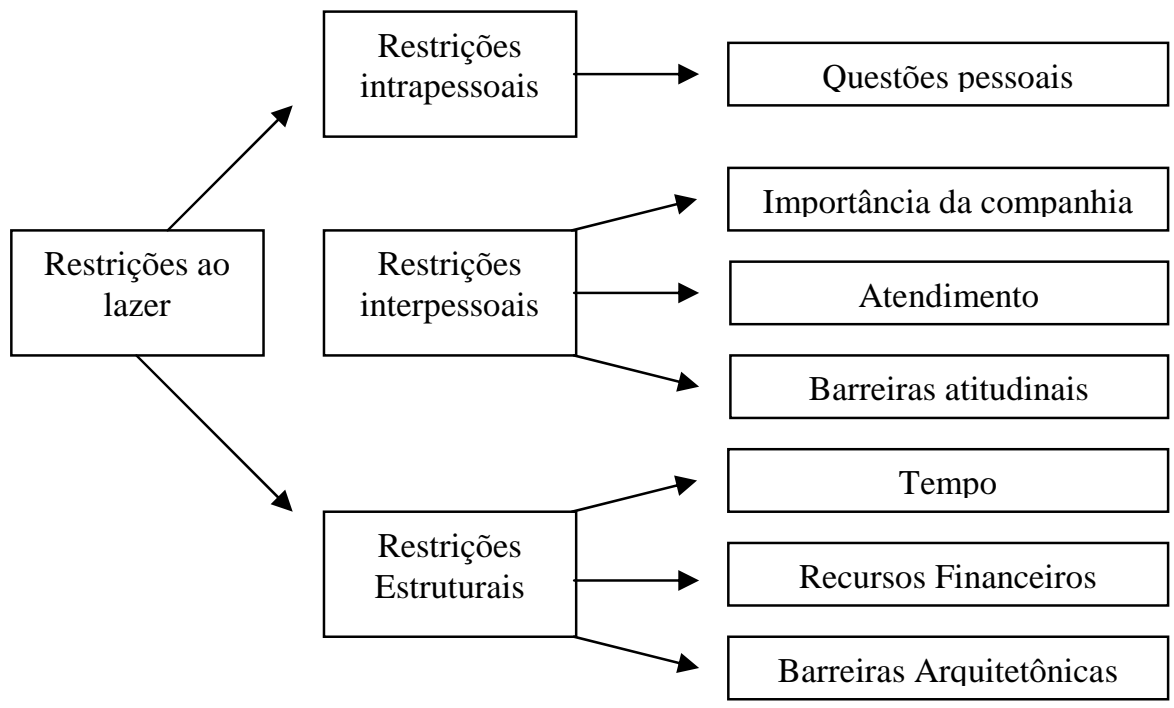

Figura 3 - Modelo de restrição ao lazer turístico para pessoas com deficiência visual

Por se tratar de um assunto ainda pouco explorado, muitas são as possibilidades de estudos futuros que podem contribuir para o avanço do conhecimento e da prática acerca das restrições ao consumo para deficientes visuais e, igualmente, para pessoas que apresentam outras deficiências. Como primeira indicação para novos esforços de pesquisa, portanto, recomenda-se fortemente que sejam conduzidos estudos sobre restrições ao consumo de lazer turístico com pessoas que tenham outras deficiências que não a visual. Em um segundo momento, sugere-se que sejam empreendidos esforços para tentar desenvolver formas de 
obter, junto a tais segmentos de mercado, informações que ajudem as organizações a superar os obstáculos impostos a tais consumidores. Além disso, em uma outra instância, pode-se planejar projetos de pesquisas que contemplem as necessidades das pessoas com deficiência visual como consumidores de outros serviços e produtos que não os de lazer turístico.

\section{Referências}

AKEL SOBRINHO, Z. Consumo de Cinema em Porto Alegre: um Estudo sobre Motivações e Atributos. Anais do Encontro da Associação Nacional dos Programas de Pós-graduação em Administração. Salvador, BA, Brasil, 2006.

ALEXANDRIS, K., \& CARROLL, B. An Analysis of Leisure Constraints Based on Different Recreational Sport Participation Levels: Results from a Study in Greece. Leisure Sciences, v. 19, 1-15, 1997.

ALMEIDA, W. Comunidade surda e o turismo de responsabilidade social: um olhar sobre as diferenças. Anais do seminário de pesquisa em turismo do Mercosul, Caxias do Sul, RS, Brasil, 4, 2006.

AMARO, L.; MEIRA, P.; CAMARGO, S.; SLONGO, L. Em que posso ajudar? O varejo e os portadores de deficiência visual. Anais do Encontro de Marketing da Anpad, Curitiba, PR, Brasil, 3, 2008.

BACH, C.; FERREIRA, S.; SILVEIRA, D. Avaliação de acessibilidade na web: estudo comparativo entre métodos de avaliação com a participação de deficientes visuais. Anais do Encontro da Associação Nacional dos Programas de Pós-graduação em Administração. São Paulo, SP, Brasil, 33, 2009.

BAHL, M. Perspectivas do turismo na sociedade pós-industrial. São Paulo: Roca, 2003.

BAKER, S. Consumer normalcy: understanding the value of shopping through narratives of consumers with visual impairments. Journal of retailing, v. 82 (1). 37-50, 2006.

BAKER, S.; HOLLAND, J. \& KAUFMAN-SCARBOROUGH, C. How consumers with disabilities perceive "welcome" in retail servicescapes: a critical incident study. Journal of Service Marketing, v. 21 (3). 160-173, 2007.

BAKER, S.; STEPHENS, D.; HILL, R. How can retailers enhance accessibility: giving consumers with visual impairments a voice in the marketplace. Journal of Retailing and Consumer Services, v. 9. 227-239, 2002.

BURNETT, J. What services marketers need to know about the mobility disabled consumer. The Journal of Services Marketing, v. 10 (3), 3-20, 1996.

CAMARGO, L. Sociologia do lazer. In: TRIGO, L. (Org.). Turismo: como ensinar, como aprender. (2 ed). São Paulo: SENAC, v. 2. 235-276, 2001.

CANTARELli, E. M. B. Barreiras Sócio-Culturais e Lazer das Pessoas Portadoras de Deficiência Física: um estudo do grupo Fraternidade Cristã de Doença e Deficiência de Campinas, SP. Dissertação de mestrado, Universidade Estadual de Campinas, Campinas, SP, Brasil, 1988. 
CARVALHO, M. A acessibilidade para cadeirantes nos atrativos turísticos culturais do centro de Porto Alegre: considerações sobre um roteiro. Trabalho de conclusão de curso, Centro Universitário Metodista, São Paulo, SP, Brasil, 2007.

CASTELL, L. Building access for the intellectually disabled. Facilities, v. 26 (3/4), 2008.

COOPER, D., \& SCHINDLER, P. Métodos de pesquisa em Administração (7 ed). Porto Alegre: Bookman, 2003.

CORRÊA, P. Acessibilidade: conceito e formas de garantia. Revista Brasileira de Educação Especial, v. 15 (1), 171-172, 2009.

COSTA, R. Acessibilidade do turismo de Belo Horizonte - Um estudo de caso da hotelaria. Anais do Seminário de Pesquisa em Turismo do Mercosul (SeminTUR), Caxias do Sul, PR, Brasil, 4, 2006.

COUTINHO, L., \& CARVALHO, J. Diversidade e ações afirmativas nas organizações brasileiras. Anais do Simpósio de Excelência em Gestão e Tecnologia, Resende, Rio de Janeiro, Brasil, 4, 2007.

COVA, B.; COVA, V. Tribal marketing: the tribalisation of society and its impact on the conduct of marketing. European Journal of Marketing, v. 36 (5/6) 595-620, 2002.

CRAWFORD, D., \& GODBEY, G. Reconceptualizing barriers to family leisure. Leisure Sciences, v. 9, 119-127, 1987.

CRAWFORD, D.; JACKSON, E.; GODBEY, G. A Hierarchical Model of Leisure Constraints. Leisure Sciences, v. 13, 309-320.

CUNHA, I., BARBOSA, M. \& KOVACS, M. A Busca por Informações e os Grupos de Referência: um Estudo Netnográfico em uma Comunidade Virtual de Turismo. Anais do Encontro de Marketing da Associação Nacional dos Programas de Pós-graduação em Administração. Curitiba, PR, Brasil, 3, 2008.

DANIELS, M. J., RODGERS, E. B. D., WIGGINS, B. P. “Travel Tales": an interpretive analysis of constraints and negotiations to pleasure travel as experienced by persons with physical disabilities. Tourism Management, v. 26, 919-930, 2005.

DARCY, S. Improving airlines practices by understanding the experiences of people with disabilities. Disponível em: <http://www.turismoadaptado.com.br/pdf/trabalhos_e_pesquisas/improving_airline_ practices_by_understanding_the_experiences_of_people_with_disabilities.pdf $>$. Acesso em: 18 out 2009.

DENCKER, A. Pesquisas em turismo: Planejamento, métodos e técnicas. (9. ed). São Paulo: Futura, 2007.

DINIZ, F., \& MOTTA, P. C. Em Busca de um Modelo de Restrição ao Lazer para os Consumidores de Mais Idade. Anais do Encontro da Associação Nacional dos Programas de Pós-graduação em Administração. Salvador, BA, Brasil, 30, 2006.

FERREIRA, S., CHAUVEL, M. \& FERREIRA, M. E-acessibilidade: tornando visível o invisível. Revista Eletrônica em Ciências Humanas, v. 6 (10), 2007.

FIRAT, F. A.; DHOLAKIA, N.; VENKATESH, A. Marketing in a postmodern world. European Journal of Marketing, v. 29 (1). 40-56, 1995.

GIL, A. Métodos e técnicas de pesquisa social (6. ed.) São Paulo: Atlas, 2008.

GILMORE, A., \& RENTSCHLER, R. Changes in museum management: a custodial or marketing emphasis? Journal of Management Development, v. 21 (10), 745-760, 2002. 
GOMES, C. Lazer enquanto estudo científico - Teses defendidas no Brasil. Dissertação de mestrado, Universidade de São Paulo. São Paulo, SP, Brasil, 2004.

GOMES, C.; REJOWSKI, M. Lazer enquanto estudo científico - Teses defendidas no Brasil. Anais do Congresso da Associação Nacional de Pós-graduação em Turismo, São Paulo, SP, Brasil, 4, 2007.

GOULART, R. As viagens e o turismo pelas lentes do deficiente físico praticante do esporte adaptado. Dissertação de Mestrado, Universidade de Caxias do Sul. Caxias do Sul, RS, Brasil, 2007.

HAIR, J.; BLACK, B.; BABIM, B.; ANDERSON, R.; TATHAM, R. Multivariate Data Analisys, 6. ed. New Jersey: Prentice-Hall., 2006.

HEIKKILÄ, J.; KALLIO, J.; SAARINEN, T.; TUUNAINEN, V. EC of groceries for elderly and disabled: a comparison of alternative service models. Information Technology \& People, v. 12 (4), 389-402, 1999.

HEMMINGTON, N., \& KING, C. Key dimensions of outsourcing hotel food and beverage services. International Journal of Contemporary Hospitality Management, v. 12, (4), 256-261, 2000.

IBGE (Instituto Brasileiro de Geografia e Estatística) CENSO DEMOGRÁFICO 2000. Disponível

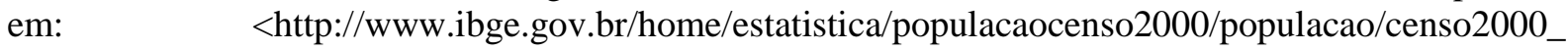
populacao.pdf $>$. Acesso em: 12 set 2009.

JACKO, J.; DIXON, M.; ROSA, H.; SCOTT, I.; PAPPAS, C. Visual profiles: a critical component of universal access. Conference on Human Factors in Computing Systems. Proceedings of the SIGCHI conference on Human factors in computing systems, 1999.

JACKSON, E. Leisure constraints/constrained leisure: special issue introduction. Journal of Leisure Research, v. 23 (4), 279-285, 1991.

JACKSON, E. Variations in the desire to begin a leisure activity: Evidence of antecedent constraints. Journal of Leisure Research, v. 22, 55-70, 1990.

JOHN, G.; REVE, T. The reliability and validity of key informants data from dyadic relationships in marketing channels. Journal of Marketing Research, v. 19 (4), 517-524, 1982.

KACZYNSKI, A.; MANNELL, R.; MANSKE, S. Leisure and risky health behaviours: a review of evidence about smoking. Journal of Leisure Research, 40 (3), 404-441, 2008.

KAUFMAN, C. Shop 'til you drop: tales from a physically challenged shopper. Journal of Consumer Marketing, v. 12 (3), 39-55, 1995.

KAUFMAN-SCARBOROUGH, C. Retailers' perceptions of the Americans with Disabilities Act: suggestions for low-cost, high impact accommodations for disabled shoppers. Journal of Consumer Marketing, v. 15 (2), 94-110, 1998.

KAY, T.; JACKSON, G. Leisure despite constraint: the impact of leisure constraints on leisure participation. Journal of Leisure Research, v. 23, 301-313, 1991.

KERLINGER, F.; LEE, H. Foundations of behaviour research. (4. ed.) Orlando: Harcourt College Publishers, 2000.

KNIGHT, A. Holidays, play and disabled children. 2008. Disponível em: <http://www.communitycare.co.uk>. Acesso em: 15 ago 2008.

LADISLAU, L. Lazer e Participação Social. A Terceira Idade, v. 13 (25), 7-25, 2002.

LAGES, S.; MARTINS, R. Turismo inclusivo: a importância da capacitação do profissional de turismo para o atendimento ao deficiente auditivo. Estação Científica, n.3, 2006. 
LOVELOCK, C.; WRIGHT, L. Serviços: marketing e gestão. São Paulo: Saraiva, 2003.

MANUAL DE RECEPÇÃO E ACESSIBILIDADE DE PESSOAS PORTADORAS DE DEFICIÊNCIA A EMPREENDIMENTOS E EQUIPAMENTOS TURÍSTICOS. Brasília, DF: Embratur/Ministério do Turismo, 2010. Disponível em:<http://www.turismo.gov.br>. Acesso em: 15 jan. 2010.

MARCELLINO, N. Estudos de Lazer: uma introdução. 4. Ed. Campinas: Editora Autores Associados, 2006.

MEIRA, P., AMARO, L. \& ALMEIDA, C. Ouvindo a voz do mercado: O varejo e os clientes portadores de deficiência auditiva. Revista gestão organizacional, v. 2 (1), 77-86, 2009.

MENDES, B.; NILMA, P. A Hospitalidade, o Turismo e a Inclusão Social para Cadeirantes. Revista Turísmo e Análise, 19, n.2,p. 329-343, 2008.

MBOGONI, M.,; SYNNEBORN, M. General disability measures in developing countries. Disponível em: <http://www.cdc.gov/nchs/about/otheract/citygroup/products/mbogoni.htm>. Acesso em: 13 set. 2009.

McKERCHER, B.; PACKER, T.; LAM, P. Travel agents as facilitators or inhibitors of travel: perceptions of people with disabilities. Tourism Management, v. 24. 465-474, 2003.

NASCIMENTO, A. P., ABREU, F. C., SILVA, R. M., \& MACEDO, V. G. Deficiência visual: uma abordagem acerca da inclusão social no turismo e no lazer em belo horizonte. Revista de Turismo, v. 3 (4), 1-15, 2008.

O’GRADY, I. Lazer junto com as Mães: restrições ao lazer infantil. Dissertação de mestrado, Pontifícia Universidade Católica do Rio de Janeiro, Rio de Janeiro, RJ, Brasil, 2007.

PENNINGTON-GRAY, L.; KERSKETTER, D. Testing a Constraints Model within the Context of Nature-Based Tourism. Journal of Travel Research, v. 40, 416-423, 2002.

POYARES, M.; GOLDFELD, M. Análise comparativa da brincadeira simbólica de crianças cegas congênitas e de visão normal. Revista Benjamin Constant, v. 40, 2008.

RAPOSO, A.; LÓPEZ, R. Conceitos de lazer em portadores de lesão medular. Revista Digital Buenos Aires, n. 49, 2002.

RAY, N. M.,; RYDER, M. E. "Ebilities" tourism: an exploratory discussion of the travel needs and motivations of the mobility-disabled. Tourism Management, 24 (2), 57-72, 2003.

RAYMORE, L.; GODBEY, G.; CRAWFORD, D.; von EYE, A. Self-Steem, Gender, and socioeconomic Status: Their Relation to Perceptions of Constraint on Leisure Among Adolescents. Journal of Leisure Research, v. 26, 99-118, 1994.

RUDDELL, J.; SHINEW, K. The socialization process for women with physical disabilities: the impact of agents and agencies in the introduction to an elite sport. Journal of leisure research, v. 38 (3), 421-444, 2006.

SANSIVIERO, S.; DIAS, C. Hotelaria e acessibilidade. Turismo - Visão e Ação, v. 7 (3), 439-453, 2005.

SASSAKI, R. Inclusão e no lazer e turismo: em busca da qualidade de vida. São Paulo: Áurea, 2003.

SCHIVITZ, T. Acessibilidade: um passo para a hospitalidade nos meios de hospedagens. Trabalho de conclusão de curso em Hospitalidade, Pontifícia Universidade Católica do Rio Grande do Sul, Porto Alegre, Rio Grande do Sul, Brasil. Orientação: Manoela Carrillo Valduga, 2007. 
SILVA, G. O significado do trabalho para o deficiente visual. Dissertação de mestrado, Pontifícia Universidade Católica de Minas Gerais, Minas gerais, Brasil. Orientação: José Newton Garcia de Araújo, 2007.

SMITH, A.; FITCHETT, J. "The first time I took acid I was in heaven": a consumer research inquiry into youth illicit drug consumption. Management Decision, v. 40. 372-382, 2002.

SOUBENIOTIS, D.; FOTIADIS, T.; MYLONAKIS, J.; HATZITHOMAS, L.; VASSILIADIS, C. The importance of facilities in the success of integrated marketing communication of hotel enterprises. European Journal of Scientific Research, v. 17, 106-116, 2007.

SVENSSON, G. Multiple informants and asymmetric interactions of mutual trust in dyadic business relationships. European Business Review, v. 18 (2), 132-152, 2006.

UPCHURCH, R., \& SEO, J. Civic responsibility and marketing positioning: complying with the Americans with Disabilities Act. Facilities, v. 14 (5/6), 48-56, 1996.

VERGARA, S. C. Projetos e relatórios de pesquisa em Administração. (10. ed.) São Paulo: Atlas, 2009.

WOODLIFFE, L. Rethinking consumer disadvantage: the importance of qualitative research. International Journal of Retail \& Distribution Management, v. 32 (11), 523-531, 2004.

YAU, M., McKERCHER, B., \& PACKER, T. Traveling with a disability: more than an access issue. Annals of Tourism Research, v. 31 (4), 946-960, 2004.

YIN, R. Estudo de caso: planejamento e métodos. (3 ed.) Porto Alegre: Bookman, 2004.

WOODLIFFE, L. Rethinking consumer disadvantage: the importance of qualitative research. International Journal of Retail \& Distribution Management, v. 32 (11), 523-531, 2004.

ZEITHAML, V.; BITNER, M. Marketing de serviços: a empresa com foco no cliente. (2. ed.) Porto Alegre: Bookman, 2003.

\section{Recebido em: 30/06/2011}

Aprovado em: 02/08/2011 (1 ${ }^{\mathrm{a}}$ versão) 01/10/2012 (2 $2^{\mathrm{a}}$ versão) 